\title{
A NOVA VELHA QUESTÃO DA ULTRA-ATIVIDADE DAS NORMAS COLETIVAS E A SÚMULA 277 DO TRIBUNAL SUPERIOR DO TRABALHO
}

\section{THE NEW OLD QUESTION OF THE JURISDICTION TO ENFORCE OF THE COLLECTIVE RULES AND THE SUMMULA 277 OF THE SUPERIOR COURT OF THE WORK}

\author{
Roberto Pessoa" \\ Rodolfo Pamplona Filho"
}

\begin{abstract}
Resumo: Tomando como ponto de partida a discussão sobre a ultraatividade das normas coletivas, analisa-se a necessidade de ser revista a súmula 277 do TST, tendo em vista que a Emenda Constitucional 45/2004 trouxe nova fundamentação normativa sobre o assunto.
\end{abstract}

Palavras-chave: Ultra-atividade. Normas coletivas. EC 45/2004. Súmula 277 do TST.

\begin{abstract}
Taking in principle the discussion about wide juridiction to enforce of the collective rules, this essay entends to analyze the need to review the Precedent number 277 from TST, from the background of the amendment to the Constitution number 45/2004 which brought a new foundamentation.
\end{abstract}

Key-words: Jurisdiction to enforce. Collective rules. Amendment to the Constitution 45/2004. Precedent n. 277/TST.

\section{INTRODUÇÃO}

Um dos temas que mais frequentemente verificamos divergência entre a jurisprudência consolidada e o que se propugna na doutrina especializada é a velha questão da ultra-atividade das normas coletivas.

Denomina-se a questão de "velha" não por estar superada, mas, sim, por ser objeto de reflexão já há muitos anos na dogmática jurídica trabalhista nacional e estrangeira.

\footnotetext{
Desembargador Ex-Presidente do Tribunal Regional do Trabalho da 5a Região, convocado para o Tribunal Superior do Trabalho.

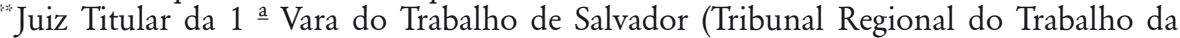
Quinta Região). Professor Titular de Direito Processual do Trabalho da Universidade Salvador - UNIFACS. Professor Adjunto da Faculdade de Direito da UFBA - Universidade Federal da Bahia. Professor da Pós-Graduação em Direito (Mestrado e Doutorado) da UFBA. Coordenador do Curso de Especialização em Direito e Processo do Trabalho do JusPodivm/BA. Mestre e Doutor em Direito do Trabalho pela Pontifícia Universidade Católica de São Paulo. Membro da Academia Nacional de Direito do Trabalho e da Academia de Letras Jurídicas da Bahia. Email: rpamplonafilho@uol.com.br.
} 
E esta "velha questão" ganhou nova roupagem e, no nosso entender, nova solução com o advento da Emenda Constitucional no 45/2004.

É o enfrentamento desta "nova velha questão" o objetivo do presente artigo. Vamos a ela!

\section{ULTRA-ATIVIDADE OU ULTRATIVIDADE? EVITANDO UMA CRÍTICA DESNECESSÁRIA...}

Antes de enfrentarmos a questão propriamente dita, uma dúvida terminológica nos assalta: ultra-atividade ou ultratividade?

A pergunta aqui é lançada apenas para explicitar que ambas as formas devem ser aceitas no uso pragmático dos tribunais.

Com efeito, em que pese o fato de que nenhuma das duas expressões esteja dicionarizada expressamente ${ }^{1}$, ambas estão consagradas pelo uso, não somente na área trabalhista, mas, também, na área civil stricto sensu e criminal.

No nosso entender, porém, a expressão ultra-atividade parece ser mais adequada, com a explicitação do prefixo "ultra", para a demonstração de se tratar de uma hipótese de produção efeitos além do originalmente previsto.

Destaque-se, inclusive, que, segundo os lexicológos, separa-se por hífen os prefixos antes das palavras seguidas de vogal e das letras " $h$ ", "r" e "s", como, por exemplo, "auto-ônibus", "ultra-sensível” e, justamente, o termo "ultra-atividade"2.

$\mathrm{Na}$ jurisprudência regional, inclusive, encontramos referência expressa ao termo, destacando-se, no particular, o Enunciado da Súmula do TRT 02- da 5o Região, que estabelece:

Súmula № 002 - ULTRATIVIDADE DE NORMAS COLETIVAS. “As cláusulas normativas, ou seja, aquelas relativas às condições de trabalho, constantes dos instrumentos decorrentes da autocomposição (Acordo Coletivo de Trabalho e Convenção Coletiva de Trabalho) gozam do efeito ultra-ativo, em face do quanto dispõe o art. 114, § 2º, da Constituição Federal de 1988, incorporandose aos contratos individuais de trabalho, até que venham a ser modificadas ou excluídas por outro instrumento da mesma natureza" (Resolução Administrativa no 19/2002 - Publicada no Diário Oficial do TRT da 5ํㅡㄹ Região, edições de 03, 04 e $05 / 6 / 2002$ ).

${ }^{1}$ Consulte-se, a título exemplificativo, FerreiraFERREIRA, Aurélio Buarque de Holanda, Novo Dicionário Aurélio da Língua Portuguesa. (FERREIRA, 1986) e, Dicionário Houaiss da Língua Portuguesa (HOUAISS; VILLAR, 2001).

${ }^{2}$ Sobre o tema, confiram-se os ensinamentos da Professora Maria de Lurdes Siqueira, mestra em Língua Portuguesa, publicados no Jornal A TARDE, de maio de 2004. 
Aqui, temos uma prova inequívoca da utilização das duas formas possíveis do vocábulo (ultratividade e ultra-ativo), além de uma previsão jurisprudencial consolidada da sua aceitação.

Mas, ainda que em breves palavras, em que consiste tal instituto?

É o que enfrentaremos no próximo tópico!

\section{EM QUE CONSISTE A ULTRA-ATIVIDADE DAS NORMAS COLETIVAS TRABALHISTAS?}

A ideia básica da ultra-atividade das normas coletivas trabalhistas consiste no reconhecimento de situações em que, esgotado o prazo previsto de vigência da norma, esta deve continuar a produzir efeitos, até que outra posterior determine sua cessação.

Para alguns, pode soar como uma ideia aparentemente revolucionária, uma vez que a concepção natural de uma norma temporário é o esgotamento de seus efeitos nas situações consolidadas durante sua vigência.

Todavia, a questão é muito mais profunda do que se possa imaginar.

De fato, o processo de negociação coletiva importa sempre em avanços e concessões, em que cada conquista consolida um posicionamento e uma garantia da categoria.

Será razoável que, a cada negociação coletiva, se tenha que "reinventar a roda”, com a negociação, partindo do zero, de cada ponto que a categoria tradicionalmente já tinha de diferenciado em relação aos demais trabalhadores?

Lança-se esta pergunta para se responder a posteriori...

Isto porque, em que pese a já demonstrada existência de divergência jurisprudencial (vide a já citada súmula 05 do Tribunal Regional do Trabalho da $5^{\circ}$. Região), o fato é que a jurisprudência consolidada no Tribunal Superior do Trabalho, embora reconheça a existência do instituto, rechaça a sua aplicação atual.

\section{A SÚMULA N № 277 DO TRIBUNAL SUPERIOR DO TRABALHO}

Estabelece a Súmula no 277 do Tribunal Superior do Trabalho:

"SUM-277 SENTENÇA NORMATIVA. CONVENÇÃO OU ACORDO COLETIVOS. VIGÊNCIA. REPERCUSSÃO NOS CONTRATOS DE TRABALHO (redação alterada na sessão do Tribunal Pleno em 16.11.2009) - Res. 161/2009, DJe divulgado em 23, 24 e 25.11 .2009

I - As condições de trabalho alcançadas por força de sentença normativa, convenção ou acordos coletivos vigoram no prazo assinado, não integrando, de forma definitiva, os contratos individuais de trabalho.

II - Ressalva-se da regra enunciada no item I o período compreendido entre 
23.12.1992 e 28.07.1995, em que vigorou a Lei $\mathrm{n}^{\mathrm{o}}$ 8.542, revogada pela Medida

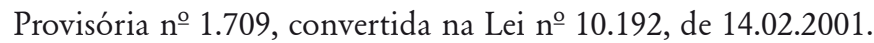

Trata-se da vigente redação do referido extrato da jurisprudência consolidada, explicitando o que a redação original ("Sentença normativa. Vigência. Repercussão nos contratos de trabalho. As condições de trabalho alcançadas por força de sentença normativa vigoram no prazo assinado, não integrando, de forma definitiva, os contratos”), editada pela Resolução 10/1988 (DJ 01, 02 e 03.03.1988), não podia dispor, em função da Lei n. 8.542 lhe ser posterior.

Ou seja, o Tribunal Superior do Trabalho reconheceu a possibilidade jurídica de incorporação das cláusulas normativas ao contrato de trabalho, mas a limitou ao período de 23.12.1992 e 28.07.1995, em que vigorou a Lei $\mathrm{n}^{\circ}$ 8.542, revogada pela Medida Provisória $\mathrm{n}^{-}$1.709, convertida na Lei $\mathrm{n} \stackrel{0}{ }$ 10.192, de 14.02.2001.

Isso porque, efetivamente, no campo do direito positivo infraconstitucional, o art. $1^{\circ}$, $\S 1^{\circ}$, da Lei $8.542 / 92$ consagrou, de forma expressa, o principio ultraativo.

Confira-se a redação do mencionado dispositivo:

Art. $1^{\circ}$ A política nacional de salários, respeitado o princípio da irredutibilidade, tem por fundamento a livre negociação coletiva e reger-se-á pelas normas estabelecidas nesta Lei.

$\S 1^{\circ}$ As cláusulas dos acordos, convenções ou contratos coletivos de trabalho integram os contratos individuais de trabalho e somente poderão ser reduzidas ou suprimidas por posterior acordo, convenção ou contrato coletivo de trabalho.

$\S 2^{\circ}$ As condições de trabalho bem como as cláusulas salariais, inclusive os aumentos reais, ganhos de produtividade do trabalho e pisos salariais proporcionais à extensão e à complexidade do trabalho, serão fixados em contrato, convenção ou acordo coletivo de trabalho, laudo arbitral ou sentença normativa, observadas dentre outros fatores, a produtividade e a lucratividade do setor ou da empresa. (Grifo nosso).

Tal dispositivo teve sua vigência revigorada, em um fenômeno muito semelhante à repristinação (não se reconhece como tal, pela sua vedação pelo art. da Lei de Introdução ao Código Civil brasileiro), pela Lei 8.880/94 (Plano de estabilidade econômica, denominado Plano Real), cujo art.26 assim preceituou:

Art. 26. Após a conversão dos salários para URV de conformidade com os arts. 19 e 27 desta Lei, continuam asseguradas a livre negociação e a negociação coletiva dos salários, observado o disposto nos $\S \S 1^{\circ}$ e $2^{\circ}$ do art. $1^{\circ}$ da Lei $n^{\circ}$ 8.542, de 1992. 
Vale destacar que o sobredito dispositivo foi evidente preparatório para uma nova concepção daquilo que se convencionou chamar de Contrato Coletivo de Trabalho 3 , tendo sobrevivido incólume até a 37ํeeção da Medida Provisória, convertida na Lei 10.192/2001, editada em complementação ao referido Plano de Estabilização.

Contudo, se a explicitação referente ao período em que a norma infraconstitucional reconheceu expressamente a ultra-atividade foi de bom tom, a extensão da restrição à eficácia pós-vigência das normas coletivas autônomas parece estar fora da vontade do legislador constituinte derivado.

É o que se pretende provar no próximo tópico.

\section{O PODER NORMATIVO DA JUSTIÇA DO TRABALHO PÓS EMENDA CONSTITUCIONAL №}

A Emenda Constitucional no 45, de 31 de dezembro de 2004, modificou substancialmente as regras básicas de competência da Justiça do Trabalho.

Com efeito, destrinchou o prolixo caput do art. 114, "enxugando-o" e deixando para nove incisos a tarefa de especificar qual é a nova competência trabalhista.

É claro que, até mesmo pelo número e extensão dos incisos, não há como se negar que a atuação da Justiça do Trabalho foi visivelmente ampliada.

Lembremos como ficou a nova redação do art. 114 da Constituição Federal:

Art. 114. Compete à Justiça do Trabalho processar e julgar:

I - as ações oriundas da relação de trabalho, abrangidos os entes de direito público externo e da administração pública direta e indireta da União, dos Estados, do Distrito Federal e dos Municípios;

II - as ações que envolvam exercício do direito de greve;

III - as ações sobre representação sindical, entre sindicatos, entre sindicatos e trabalhadores, e entre sindicatos e empregadores;

IV - os mandados de segurança, habeas corpus e habeas data, quando o ato questionado envolver matéria sujeita à sua jurisdição;

$\mathrm{V}$ - os conflitos de competência entre órgãos com jurisdição trabalhista, ressalvado o disposto no art. 102, I, o;

VI - as ações de indenização por dano moral ou patrimonial, decorrentes da relação de trabalho;

3 "No Brasil, os instrumentos jurídicos geram efeitos apenas no período de vigência. O ideal é que os efeitos sejam permanentes até que um novo instrumento revogue o antigo, ou a demonstração de onerosidade seja declarada em processo de renúncia, movido pelo interessado. Esta é a tendência mais marcante nos países com experiências trabalhistas mais democráticas e perenes” (SIQUEIRA NETO, 1994). 
VII - as ações relativas às penalidades administrativas impostas aos empregadores pelos órgãos de fiscalização das relações de trabalho;

VIII - a execução, de ofício, das contribuições sociais previstas no art. 195, I, a, e II, e seus acréscimos legais, decorrentes das sentenças que proferir;

IX - outras controvérsias decorrentes da relação de trabalho, na forma da lei.

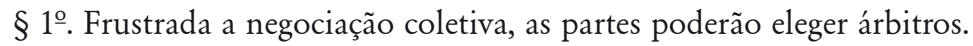

$\S 2$. Recusando-se qualquer das partes à negociação coletiva ou à arbitragem, é facultado às mesmas, de comum acordo, ajuizar dissídio coletivo de natureza econômica, podendo a Justiça do Trabalho decidir o conflito, respeitadas as disposições mínimas legais de proteção ao trabalho, bem como as convencionadas anteriormente.

$\S 3$ ㅇ. Em caso de greve em atividade essencial, com possibilidade de lesão do interesse público, o Ministério Público do Trabalho poderá ajuizar dissídio coletivo, competindo à Justiça do Trabalho decidir o conflito.

Ora, o art. 114, § 2oำ da Constituição Federal de 1988 já contemplava o poder normativo da Justiça do Trabalho na sua redação original.

Naquele momento, a redação ressalvava as condições legais ou convencionais mínimas de proteção ao trabalho.

Contudo, a EC 45 deu nova conformação aos Dissídios Coletivos, enfatizando, porém, que a atuação do Poder Judiciário Trabalhista, na espécie, deverá respeitar "as disposições mínimas legais de proteção ao trabalho, bem como as convencionadas anteriormente” (Grifo nosso).

A inserção procedida pelo reformador constituinte é de uma contundência que não pode ser desprezada.

O Poder Judicial-Normativo não pode reduzir as cláusulas de natureza econômica, estejam ou não em vigor, as disposições convencionais que as contêm.

Assim, se o que for decidido pelo Poder Judiciário, no exercício do seu poder normativo, terá sempre eficácia temporal limitada, o mesmo não deve ser dito das normas pactuadas no exercício da autonomia coletiva da vontade.

E é assim porque há, efetivamente, a ultra-atividade dessas cláusulas enquanto não sobrevier negociação coletiva que resulte em sua supressão.

A regra Constitucional se concilia, no plano lógico, com o princípio da autodeterminação coletiva (art. 7º $, \mathrm{XXVI}, \mathrm{CF} / 88$ ), dado que o eventual interesse de rever conquistas obreiras motivará o empregador a iniciar a negociação coletiva de trabalho, expondo-se visceralmente a outras eventuais demandas.

Registre-se, inclusive, que há categorias profissionais econômicas (a exemplo, dos Rodoviários e Empresas de Transporte Rodoviário do Estado da Bahia) que, 
tradicionalmente, consagram na data-base o princípio ultra-ativo das cláusulas normativas, reduzindo, ou revisando aquelas destinadas à correção salarial ou mesmo percentual de horas extras, intervalo intrajornada etc.

\section{A RAZOABILIDADE DA NECESSIDADE DE REVISÃO DA SÚMULA № 277}

Para que o tema aqui defendido não soe simplesmente como um discurso de um voto vencido, mas, sim, como uma ponderada sugestão de revisão do entendimento até aqui consolidado - realizado em premissas constitucionais anteriores - parece-nos razoável demonstrar que o próprio Tribunal Superior do Trabalho tem flexibilizado tal entendimento, admitindo a ultra-atividade em casos em que a vantagem foi mantida após a extinção do convenio.

É o caso, apenas a título exemplificativo, da orientação jurisprudencial $n^{\circ}$ 41, da SDI-I - Seção de Dissídios Individuais I, que preceitua:

OJ-SDI1-41 ESTABILIDADE. INSTRUMENTO NORMATIVO. VIGÊNCIA. EFICÁCIA (inserida em 25.11.1996).

Preenchidos todos os pressupostos para a aquisição de estabilidade decorrente de acidente ou doença profissional, ainda durante a vigência do instrumento normativo, goza o empregado de estabilidade mesmo após o término da vigência deste.

Além disso, diante da possibilidade do reconhecimento constitucional da pós-eficácia das normas coletivas, vale relembrar que tal posicionamento é perfeitamente constitucional com a concepção doutrinária assentada sobre o prazo de validade dos instrumentos normativos trabalhistas.

Com efeito, os opositores à corrente doutrinária que proclama o efeito "ultratemporal” das cláusulas estatuídas em instrumentos normativos provocam o debate acenando para a disposição contida no $\S 3^{\circ}$ do art. 614 da CLT, pois, segundo tal linha de raciocínio, o legislador fixou, por esse dispositivo, o limite de duração das normas coletivas, vedando uma transposição para os contratos de trabalho pactuados individualmente durante a sua vigência por tempo indeterminado.

Argumentam, em síntese, que, se assim não fosse, inconsistente seria a obrigação de se estipular no instrumento normativo a validade de, no máximo, dois anos, pois é vedado se fixar prazo superior.

Para elucidar a controvérsia, impõe-se o estudo inicial sobre a natureza jurídica das cláusulas inseridas nos instrumentos normativos, a fim de se verificar a sua identidade com o tempo de duração. A fonte doutrinária resolve a questão apontando as diferenças existentes entre as cláusulas instituídas nos respectivos instrumentos mediante a classificação de obrigacionais ou normativas. 
Nessa linha classificatória, lecionava Octávio Bueno Magano (1985) que as cláusulas normativas são aquelas "que correspondem ao conceito de condições de trabalho, aptas a se tornarem parte integrante de contratos individuais, conceito esse que se reflete no art. 611 da CLT”.

Tendo-as presente, pode-se dizer que constituem condições de trabalho as cláusulas concernentes à remuneração, às horas de trabalho, aos períodos de repouso etc. Enquanto as cláusulas obrigacionais dos instrumentos normativos (Acordo - Convenção) são definidas como aquelas

que geram direitos e obrigações entre as partes convenentes, e dividem-se em cláusulas típicas e atípicas. As primeiras correspondem aos deveres de paz e de influência; as últimas dizem respeito aos mecanismos de administração da convenção coletiva, como a instituição de comissão encarregada de dirimir controvérsias dela emergentes. As cláusulas atípicas podem ser instrumentais, como na hipótese acima figurada, ou não instrumentais, quando se referem não à satisfação de interesses dos trabalhadores ou empregadores, mas aos interesses dos próprios sindicatos convenentes (MAGANO, 1985, p. 503).

Para o professor baiano e magistrado Washington da Trindade (1982, p. 87), essa classificação se impõe como meio para se decidir sobre a ultra-atividade das cláusulas dos precitados instrumentos, nos seguintes termos:

É preciso distinguir, todavia, entre duração de Acordo e projeção de suas normas. As obrigações para as partes signatárias e que constituem conteúdo obrigacional de acordo, extinguir-se-ão com o término de sua vigência. Já as disposições que são estabelecidas para as relações individuais de trabalho e que constituem o conteúdo normativo do Acordo não desaparecem com o término da duração; projetam-se sobre os contratos de trabalho em curso, neles se inserem, passam a ser, daí por diante, normas de cada um em dois contratos individuais, neles encontrando o fundamento de sua perdurabilidade, mesmo após o termo final do Acordo Coletivo.

Este é, também, o magistério do mestre Pinho Pedreira (1996, p. 134):

Cláusulas obrigacionais são as que criam deveres para as próprias partes (p.ex., os sindicatos, na convenção), como as sanções por seu inadimplemento, a criação de comissões paritárias para dirimirem divergências quanto à sua interpretação, as que impõem o dever de paz ou de influência junto aos membros da categoria no sentido da observância das obrigações que lhes imponha o acordo ou a sentença, a instituição de processos de recurso e de mecanismos de conciliação e arbitragem a criação de obras sociais, como colônias de férias e creches. É indubitável que as cláusulas dessa natureza não gozam de ultratividade. A sua vigência cessa com a do instrumento normativo que as encerre. 
Muito diferente é o que se passa com as cláusulas normativas, aquelas que predeterminam o conteúdo dos contratos individuais do trabalho, salvo quando estes estipulam condições mais favoráveis do que as nelas consignadas.

Do entendimento sobredito, pode-se concluir neste tópico que, apenas as cláusulas obrigacionais perdem eficácia após o prazo de vigência estipulado na convenção, diante da sua natureza contratual, enquanto as demais, de conteúdo normativo, ganham corpo reflexivo sobre os contratos individuais, por força atrativa advinda da sua projeção.

E, resumindo o pensamento da corrente doutrinária favorável à incorporação, reside a lição do insigne professor Washington da Trindade (1982, p. 87):

Há uma função receptícia do contrato individual e uma função outorgante do Acordo Coletivo, acasalando-se para a transposição do direito que sai da esfera do Acordo Coletivo para penetrar no âmbito do contrato individual como norma que por si se manterá não necessitando mais do Acordo Coletivo para se fundamentar. É esse o efeito ultratemporal dos Acordos Coletivos, não expressos em nossas leis, mas consubstanciando uma fórmula aceita como própria do instituto.

Ao lado disso, o presente estudo nos obriga a uma pesquisa no direito estrangeiro, a fim de observarmos a posição adotada pelos países mais representativos e cuja doutrina tem repercussão no Brasil.

Dentro desse contexto, encontramos países que admitem a supressão ou a redução de vantagens previstas em instrumentos anteriores, em geral acordos e convenções, quando da celebração de um novo instrumento, a exemplo da Áustria, Chile, Colômbia, Espanha, França, Holanda, Itália, Polônia, Alemanha e Suíça.

Por outro lado, há países que inadmitem a modificação, salvo se mais benéfica para o trabalhador, nestes se incluindo, a título exemplificativo, Argentina, Bélgica, México, Paraguai, Venezuela e Uruguai, dentre outros.

\section{CONSIDERAÇÕES FINAIS}

Ante o exposto, a título de considerações finais, é possível sistematizar as seguintes conclusões:

1) A tese da ultra-atividade das normas coletivas das oriundas da fonte de produção autonôma teve previsão legal específica de aplicação no período compreendido entre 23.12.1992 e 28.07.1995, em que vigorou a Lei $\mathrm{n}^{\circ}$ 8.542, revogada pela Medida Provisória $\mathrm{n}^{-}$1.709, convertida na Lei $\mathrm{n}^{-}$10.192, de 14.02.2001; 
2) A Súmula 277 do Tribunal Superior do Trabalho buscou uniformizar a interpretação sobre o tema, adotando teoria negativa da aplicabilidade, ante a revogação expressa da previsão legal autorizadora;

3) Com o advento da nova redação do art. 114 da Constituição Federal, por força da Emenda Constitucional no $45 / 2004$, a menção, no seu $\S 2^{\circ}$, de que devem ser "respeitadas as disposições mínimas legais de proteção ao trabalho, bem como as convencionadas anteriormente", traz, como novidade, a referência ao respeito às disposições mínimas convencionadas anteriormente, o que significa nova fundamentação normativa para acolhimento da tese da ultratividade das normas coletivas;

4) Considerando o fato novo, decorrente do exercício do poder constituinte derivado, é razoável reconhecer-se a necessidade de revisão da Súmula no 277 ;

5) A adoção da teoria da ultra-atividade das normas coletivas, além de estimular a negociação coletiva e atuação sindical, mostra-se perfeitamente compatível com a legislação estrangeira, afinando-se o Brasil com outros sistemas normativos correlatos.

\section{REFERENCIAS}

FERREIRA, Aurélio Buarque de Holanda. Novo Dicionário Aurélio da Língua Portuguesa. 2. ed. Rio de Janeiro: Nova Fronteira, 1986.

GAGLIANO, Pablo Stolze; PAMPLONA FILHO, Rodolfo. Novo Curso de Direito Civil: parte geral. 9. ed. São Paulo: Saraiva, 2007. v. 1.

HOUAISS, Antônio; VILLAR, Mauro de Salles. Dicionário Houaiss da Língua Portuguesa. Rio de Janeiro: Objetiva, 2001.

MAGANO, Otávio Bueno. Convenção coletiva de trabalho, curso de Direito do Trabalho em homenagem a Mozar Victor Russomano. São Paulo: Saraiva, 1985.

PAMPLONA FILHO, Rodolfo. A Nova Competência da Justiça do Trabalho (uma contribuição para a compreensão dos limites do novo Art. 114 da Constituição Federal de 1988). Revista LTr. legislação do trabalho, São Paulo, v. 70, n. 1, p. 38-49, jan. de 2006.

PESSOA, Roberto. A ultra-atividade das normas coletivas. In: RIBEIRO, Lélia Guimarães Carvalho; PAMPLONA FILHO, Rodolfo. Direito do Trabalho: estudos em homenagem ao Prof. Luiz de Pinho Pedreira da Silva. São Paulo: LTr, 1996. 
SILVA, Luís de Pinho Pedreira da. Principiologia do Direito do Trabalho. Salvador: Ed. Contraste, 1996.

SIQUEIRA NETO, J. F. Trabalhadores: a modernização necessária. Teoria e Debate, n. 23, dez. 93/jan./fev. 1994. Disponível em: <http://www.fpabramo. org.br/conteudo/trabalhadores-modernizacao-necessaria>. Acesso em: 10 jun. 2010.

TRINDADE, Washington da. O superdireito nas relações de trabalho. Salvador: ed. Distribuidora de Livros de Salvador, 1982.

Artigo recebido em 28/04/10 e aprovado para publicação $06 / 09 / 10$ 
